Arch. Vet. Scienc. 3(1):21-24, 1998

Printed in Brazil

\title{
MÉTODO PARA O ESTUDO DOS EFEITOS PRODUZIDOS POR HERBICIDAS HETEROAUXÍNICOS CLOROFENOXIACÉTICOS SOBRE OS MECANISMOS DA ABSORÇÃO INTESTINAL E DO TRANSPORTE ATIVO
}

\author{
HEITOR S. G. MEDINA; VALTER S. QUEIROZ; CÉLIA REGINA B. DE MESQUITA
}

Laboratório de Piscicultura, Setor de Ciências Agrárias, Universidade Federal do Paraná e Laboratório de Biodetecção, Instituto Ambiental do Paraná - IAP, Secretaria de Estado do Meio Ambiente, Curitiba, PR.

\begin{abstract}
Dichlorophenoxyacetic heteroauxinic herbicides were identified as the chemical agressors responsible for the 1986 environmental impacts at Miranda and Betione rivers (MS) and 1988 at Guaraqueçaba bay (PR). A special methodology has been then developed aiming to evaluate the effect of such chemical agressors on the mechanisms of absorption and active transport by the small intestine of vertebrates, mainly fish and mammals.
\end{abstract}

Key Words: Heteroauxinic herbicides; chlorophenoxyacetates; intestinal absorption; active trasnport.

RESUMO - Estudos de desastres ecológicos ocorridos nos rios Miranda e Betione (MS) e na baia de Guaraqueçaba (PR), causando grande mortandade de peixes, foram identificados como tendo sido causados por herbicidas heteroauxínicos diclorofenoxiacéticos. Foi desenvolvida, então, no presente trabalho, metodologia destinada a avaliar, no intestino delgado de vertebrados, particularmente de peixes e de mamíferos, as modificações que podem ocorrer nos mecanismos da absorção e do transporte ativo da alça intestinal funcionante submetida aos efeitos de herbicidas heteroauxínicos.

Palavras-Chave: Herbicidas heteroauxínicos; clorofenoxiacetatos; absorção intestinal; transporte ativo.

\section{Introdução}

Os impactos ambientais químicos ocorridos nos rios Miranda e Betione (MS) em 1985-1986 (MEDINA e BISCAIA de MIRANDA, 1986) e em Guaraqueçaba, Antonina e Morretes (PR) em 1988 (MEDINA e WAHRHAFTIG, 1990), pareciam confirmar as suspeitas de que herbicidas heteroauxínicos clorofenoxiacéticos teriam sido os responsáveis pela mortandade de peixes que se verificou naquelas ocasiões.

Entretanto, a participação dos herbicidas agrícolas heteroauxínicos como causa direta de acidentes ecológicos ambientais, não pôde ser confirmada na ocasião em virtude dos sinais e sintomas das lesões produzidas pela intoxicação por eles causada não serem, até então, bem conhecidos. Esses fatos ensejaram, em nossos laboratórios, diversas pesquisas sobre os possíveis efeitos causados por diclorofenoxiacetatos em sistemas biológicos (GREMSKI et al, 1988; MERLIN, 1989; MANGILI et al, 1989; TARTARUCH et al, 1990; WAHRHAFTIG et al, 1990; MERLIN et al, 1990).

$\mathrm{Na}$ seqüência desses estudos, foi desenvolvida metodologia (MEDINA e BACILA, 1998) destinada a estudar, diagnosticar e caracterizar agressores químicos com base nas lesões e nas alterações funcionais causadas pela intoxicação sofrida por bioindicadores que comungam com o meio ambiente poluído.

Por suas propriedades morfológicas e funcionais, as subestruturas jejunais do intestino delgado de peixes e de mamíferos foram escolhidas para estudar in anima villi as ações e os efeitos nocivos produzidos pelas formulações herbicidas heteroauxínicas diclorofenoxiacéticas. No presente trabalho, o intestino delgado do rato (Rattus rattus norvaegicus, Berkenhout) foi escolhido como alvo biológico para estudar os efeitos produzidos pelas heteroauxínas diclorofenoxiacéticas sobre os mecanismos do transporte ativo e da absorção intestinais. Para tanto, foi idealizado e é proposto neste trabalho, um método constituído por um sistema de aquecimento acoplado a um outro de transporte e de perfusão o qual facilita conhecer e estudar in vitro e in vivo as modificações funcionais e morfológicas que ocorrem no aparelho gastro-intestinal de vertebrados quando os referidos animais ingerem ou permanecem em contato com águas poluídas por formulações herbicidas heteroauxínicas clorofenoxiacéticas, bem como por outros agressores químicos principalmente do grupo dos agrotóxicos.

\section{Materiais e Métodos}

Material biológico. Foram utilizados nestes estudos o rato, Rattus rattus norvaegicus, Berkenhout, do Biotério do Instituto de Tecnologia do Paraná e o corimbatá, Prochylodus scrofa, do Laboratório de Aquicultura da Pontificia Universidade Católica do Paraná.

Sistema de perfusão da alça intestinal. A fim de reproduzir em laboratório as condições ideais para estudar "in vitro" os efeitos moleculares nocivos que 
as heteroauxinas diclorofenoxiacéticas cloradas produzem nos referidos bioindicadores ambientais, foi montado um duplo sistema perfundente (Fig.1) que utiliza uma alça intestinal isolada dos bioindicadores em questão, como estrutura biológica de experimentação.

A metodologia utilizada na presente experimentação está constituída por um duplo sistema de líquidos de perfusão em circulação fechada os quais trabalham em separado e independentes cada qual cumprindo finalidades específicas, mas que se complementam e colaboram para manterem exatos os parâmetros do experimento.

De acordo com o esquema mostrado na Fig. 1, os dois sistemas de líquidos de perfusão, trabalham em conjunto, acionados que são por três mecanismos líquido-propulsores, A-1, A-2 e B7.

Uma bomba peristáltica (A-2) movimenta as soluções perfundentes as quais contêm, dissolvidas, as substâncias que devem ser transportadas, garantindo permanente contacto com a mucosa jejunal isolada, submersa (B-3) em óleo de parafina. Nesta situação, a alça intestinal perfundida passa a gotejar pequenas esférulas liquidas que contêm, em solução, as substâncias que foram absorvidas pela mucosa intestinal. Essas esférulas são, então, coletadas em (B-3) para a sua correspondente análise, permitindo, assim, estabelecer todos os parâmetros quantitativos do processo de absorção intestinal pertinente.

Estações intermediárias de aquecimento bem como sensores de $\mathrm{pH}$ podem ser intercalados no circuíto (A2) a fim de auxiliar na manutenção da temperatura e do potencial hidrogeniônico no sistema de transporte (B-3, B-4, B-5, B-6).

$\mathrm{A}$ intercalação de um eletródio de oxigênio (B-8) entre os ramos ascendente e descendente do circuíto (B) permite medir na solução perfundente, o consumo de oxigênio.

Fig. 1. Representação esquemática do sistema operacional para o estudo "in vitro" do efeito de agressores químicos do grupo dos clorofenoxiacetatos, sobre a absorção intestinal. Lado (A) = Sistema aquecedor; (A-1) = Recipiente contendo, em destaque vermelho, água glicerinada a $2 \%$ aquecida a $30^{\circ} \mathrm{C}$; (MTPS) = Mecanismo termo-propulsor da solução glicerinada aquecedora e perfundente do lado (B); Lado (B) = Sistema transportador; (A-2) = Bomba peristáltica controladora da pressão e da temperatura da solução transportadora, em destaque amarelo em (B-3), no lado (B); (B-4) = Bomba borbulhadora que movimenta, reaquece e reoxigena em (B-5) a solução transportadora, em destaque amarelo, no circuito (B-3, B-4, B-5, B-6 e B-7), no lado (B); (B-5) = Circuito reaquecedor e reoxigenador; $(\mathrm{B}-6)=$ Linha limitante $(\mathrm{x}-\mathrm{y})$ de $(\mathrm{Ba} \backslash \mathrm{Bb}) ;(\mathrm{B}-7)=$ Sistema perfusor; (B-8) = Eletródio de oxigênio adaptável ao sistema transportador. 


\section{Resultado e Discussão}

Desenvolvimento da experimentação. No presente trabalho é mostrado um experimento padrão de absorção intestinal de glicose utilizando alça intestinal de rato albino (Rattus rattus norvaegicus, Berkenhout, pelo método ora descrito.

Um exemplar de rato macho de $177 \mathrm{~g}$, anestesiado com eter sulfúrico, foi utilizado para a obtenção da alça jejunal. Uma vez canulada na porção proximal e convenientemente lavada em Tyrode aquecido a $36^{\circ} \mathrm{C}$, a fim de retirar o conteúdo intestinal, a alça jejunal é canulada em suas porções distais, as cânulas sendo então conectadas (em B-3) à bomba peristáltica, com a alça mergulhada em óleo mineral (Nujol). A bomba peristáltica impulsiona então a solução de Tyrode ( $\mathrm{pH} 7,35$ 7,45), convenientemente oxigenada, contendo em solução, a substância ou substâncias em estudo. A solução de Tyrode utilizada é constituída de uma mistura em partes iguais das soluções de Tyrode I e
II. A solução de Tyrode I contém $\mathrm{NaCl}, 8,0 \mathrm{~g}, \mathrm{KCl}$, 0,2 g, $\mathrm{CaCl}_{2}, 0,2 \mathrm{~g} \mathrm{e} \mathrm{MgCl}_{2}, 6 \mathrm{H}_{2} \mathrm{O}, 0,1 \mathrm{~g} \mathrm{e} \mathrm{H}_{2} \mathrm{O}$, qsp $100 \mathrm{ml}$. A solução de Tyrode II é preparada com $\mathrm{NaH}_{2} \mathrm{PO}_{4}, \mathrm{H}_{2} \mathrm{O}, 0,05 \mathrm{~g}$ e $\mathrm{NaHCO}_{3}, 1 \mathrm{~g}$, dissolvidos em $\mathrm{H}_{2} \mathrm{O}$, qsp $100 \mathrm{ml}$. A solução de trabalho é preparada com mistura de $100 \mathrm{ml} \mathrm{de}$ cada uma das soluções, completando-se o volume final para $1000 \mathrm{ml}$, acrescentando-se 1,2 a 2,0 $\mathrm{g}$ de glicose, o pH final sendo ajustado para 7,35 - 7,45 com $\mathrm{HCl}$.

A partir daí, a alça intestinal perfundida passa a gotejar pequenas esférulas liquidas que contêm, em solução, as substâncias que foram absorvidas e transportadas pela mucosa intestinal, no caso a glicose utilizada no experimento. As esférulas líquidas são, então, coletadas em espaços de tempo adequados e submetidas a análises químicas específicas para cada caso.

A Fig. 2 mostra os resultados do estudo de absorção intestinal da glicose pela alça jejunal de rato.

Fig. 2. Rítmo da absorção intestinal de glicose pela alça jejunal isolada de rato. A alça intestinal foi perfundida com solução de Tyrode contendo 128,03 mg de glicose por $100 \mathrm{ml}$. A concentração de glicose na solução perfundente foi medida no início do experimento e, depois, na solução perfundida, colhida na forma de gotas que atravessavam a alça jejunal, e transitavam pelo óleo mineral em direção a tubos do tipo vacuntainer contendo fluoreto de sódio e que foram recolhidos aos 30, 60 e 90 minutos do início do experimento. Ao final, foi determinada a concentração residual de glicose no líquido perfundente. Foram encontradas as seguintes concentrações de glicose em mg/100 ml: 128,03, no início do experimento; $37,23,26,78$ e 25,10 no material colhido aos 30, 60 e 90 minutos, respectivamente.

Verifica-se, assim, que a metodologia proposta para o estudo da absorção intestinal é adequada para experimentos que sejam delineados com a finalidade de analisar as lesões morfológicas e funcionais causadas pela intoxicação de bioindicadores ambientais quando os animais ingerem ou permanecem demoradamente em contato com águas poluídas pelas formulações heteroauxínicas de emprego agrícola.

Por sua natureza e suas características biológicas e funcionais, as subestruturas jejunais foram escolhidas como "alvo biológico" para estudar as ações e os efeitos nocivos produzidos por essas formulações, sobre os mecanismos do trans;porte ativo e da absorção jejunais.

A metodologia presente permite ainda medir os 
níveis de oxigênio consumido pelo orgão isolado bem como as variações de $\mathrm{pH}$ na solução perfundente durante os processos de perfusão intestinal, neste caso pela intercalação de sensores especiais no circuito (B) da preparação. As medidas de níveis de oxigênio são levadas a efeito por polarografia com eletródio de oxigênio, segundo VOSS et al. (1963) e MEDINA et al. (1967).

\section{Agradecimentos}

Aos pesquisadores Élcio Merlin e Lígia Maria Salvo pelo auxílio técnico emprestado ao longo do presente trabalho.

\section{REFERÊNCIAS BIBLIOGRÁFICAS}

GREMSKI, W.; SOUZA, S.J.; WAL, D.; MEDINA, H.S.G.; QUINTANILHA, M. Aspecto ultraestrutural da glândula submandibular do rato adulto tratado com fitormônios, clorados. Anais. VI Congresso Brasileiro de Biologia Celular, pg. 10, Art. 20, 1988 .

MANGILI, O. C.; TARTARUCH, A.L.; CIPRIANO, I.M.; MEDINA, H.S.G.; GREMSKI, W. Perfil da reatividade nefrotóxica do herbicida Tordon. Anais. XXIV Congresso Brasileiro de Fisiologia. Caxambu, 1989.

MEDINA, H.S.G.; VOSS, D.O.; BACILA, M. The determination of oxygen uptake from perfusion liquids by isolated whole heart. An. Acad. Bras. Cien. 39:1, 1967.

MEDINA, H.S.G.; BISCAIA DE MEDEIROS, M.L. Relatório à SUREHMA sobre o desastre ecológico ocorrido no Rio Miranda (MS) provocado por fenoxiacetatos. Curitiba, 1986.
MEDINA, H.S.G.; WAHRHAFTIG, C. Relatório à SUREHMA sobre o desastre ecologico ocorrido em 1988 em Guaraqueçaba, Antonina e Morretes, PR. provocado por fenoxiacetatos. Curitiba, 1990.

MEDINA, H.S.G.; BACILA, M. Métodologia para o estudo de agressores químicos causadores de impacto ambiental (em publicação), 1998.

MERLIN, E. Contribuição ao estudo da iatrogênese p;roduzida pela mistura herbicida 2,4-D + Picloram 64/260, éster trisisopropanolamina em peixes e mamíferos. Estudo morfológico. Dissertação de Mestrado, Curso de Pós-Graduação em Ciências Veterinárias, Universidade Federal do Paraná, Curitiba, 1989.

MERLIN, E.; WAHRHAFTIG, C.; MEDINA, H.S.G. Estudo histológico do efeito de clorofenoxiacetatos em peixes. I Simpósio de Ciências Médicas e Biológicas, Curso de PósGraduação em Ciências Veterinárias, UFPR. Anais, 1990.

TARTARUCH, A.L.; CIPRIANO, I.; MEDINA, H.S.G.; GREMSKI, W.; MANGILI, O.C. Perfil da reatividade nefrotóxica do herbicida Tordon. I Simpósio de Ciências Médicas e Biológicas, Curso de Pós-Graduação em Ciências Veterinárias, UFPR. Anais, 1990.

VOSS, D.O.; COWLES, J. C.; BACILA, M. A new oxygen electrode for the determination of respiration and oxydative phosporylation. Anal. Bioch. 6:211, 1963.

WAHRHAFTIG， C.; MERLIN， E.; CURIAL， O.; MEDINA, H.S.G. Estudos histológicos da ação de herbicidas do grupo dos clorofenoxiacetatos sobre o fígado e o rim de aves e mamíferos. I. Simpósio de Ciências Médicas e Biológicas, Curso de PósGraduação em Ciências Veterinárias, UFPR. Anais, 1990. 